\title{
Gene therapy for arthritis
}

\author{
Russell S. Traister $\cdot$ Raphael Hirsch
}

Received: 28 August 2007/Accepted: 9 October 2007/Published online: 5 January 2008

(C) Japan College of Rheumatology 2007

\begin{abstract}
Arthritis is among the leading causes of disability in the developed world. There remains no cure for this disease and the current treatments are only modestly effective at slowing the disease's progression and providing symptomatic relief. The clinical effectiveness of current treatment regimens has been limited by short halflives of the drugs and the requirement for repeated systemic administration. Utilizing gene transfer approaches for the treatment of arthritis may overcome some of the obstacles associated with current treatment strategies. The present review examines recent developments in gene therapy for arthritis. Delivery strategies, gene transfer vectors, candidate genes, and safety are also discussed.
\end{abstract}

Keywords Rheumatoid arthritis - Gene therapy ·

Gene transfer · Inflammation · Cytokines

\section{Introduction}

Rheumatoid arthritis (RA) is the most common inflammatory disorder, affecting approximately $0.5-1 \%$ of the North American adult population. It causes significant pathology and functional impairment in affected individuals. RA is a multifactorial disease whose main risk factors include genetic susceptibility, sex and age, smoking, infectious agents, hormones, diet, and socioeconomic and ethnic factors [1]. Those afflicted by RA report a decrease in quality of life measures such as persistent pain, functional

R. S. Traister $\cdot$ R. Hirsch $(\square)$

Division of Rheumatology, Children's Hospital of Pittsburgh,

University of Pittsburgh School of Medicine, 3705 Fifth Avenue,

Pittsburgh, PA 15213, USA

e-mail: raphael.hirsch@chp.edu disability, fatigue, depression, and an inability to perform daily tasks [2]. RA is also a significant burden on the health care system, averaging between $\$ 2,800-\$ 28,500$ per patient per year for direct and indirect costs in developed countries [3]. Although the pathogenesis of RA is not completely understood, specific HLA-DR genes, autoantibody and immune complex production, $\mathrm{T}$ cell antigen-specific responses, networks of cytokine production, and a hyperplastic synovium have all been shown to play a role.

RA primarily affects diarthrodial joints of the hands and feet. These joints are normally lined by a thin cell layer (1-3 cells) of both type I (macrophage-like) and type II (fibroblast-like) synoviocytes. In RA, the joint is inflamed and the synovium becomes hyperplastic, creating a pannus of synovial tissue comprised of CD4+ T cells, B cells, mast cells, dendritic cells, macrophages, and synoviocytes that invade and destroy nearby cartilage and bone. Neutrophils accumulate in the synovial fluid and also contribute to the destructive processes $[4,5]$. Macrophages and fibroblastlike synoviocytes (FLS) secrete inflammatory cytokines, such as TNF $\alpha$, IL- $1 \beta$, and IL- 6 , all of which contribute to cartilage and bone destruction. They have been implicated as major contributors to many aspects of RA, including inflammatory cell infiltration, fibrosis, and $\mathrm{T}$ cell proliferative responses $[6,7]$. These cytokines are thought to act primarily through MAP kinase and nuclear factor $\kappa \mathrm{B}$ $(\mathrm{NF} \kappa \mathrm{B})$ signaling pathways to activate transcription factors that turn on genes for chemokines and cell adhesion molecules, along with extracellular matrix degrading enzymes like matrix metalloproteinases (MMPs). Chemokines and chemokine receptors have also been linked to RA [6, 8, 9].

Initial treatment strategies for RA include drugs such as non-steroidal anti-inflammatory drugs (NSAIDs) and glucocorticoids. While providing pain relief and decreased joint swelling, these drugs are unable to stop the progression 
of RA [10]. This led to the use of small molecules like methotrexate that were demonstrated to slow disease progression. For many decades these disease-modifying agents of rheumatic disease (DMARDs) were the best treatment option for RA. In recent years, a further understanding of the disease process has led to the development of biologic DMARDs primarily aimed at neutralizing the effects of proinflammatory cytokines. The most successful agents in this class are anti-TNF- $\alpha$ molecules and IL- $1 \beta$ blocking agents. Based on improvement criteria set forth by the American College of Rheumatology (ACR), these drugs are more effective than treatment with methotrexate alone. Even so, less than half of the patients show improvement of at least $50 \%$ in their ACR scores. In addition, the half-life of these drugs is relatively short and they require frequent systemic administration in order to be effective [11]. Gene transfer strategies have the potential to overcome some of these limitations, potentially leading to increased efficacy and decreased frequency of administration.

\section{Gene delivery strategies}

Although the majority of inflammation in RA is localized to the joints, there are systemic components to the disease. Therefore, when developing treatment strategies, one must consider whether the therapy should be delivered locally or systemically. Local administration is attractive because it has less potential for side effects and the treatment is delivered directly to the joint, the main site of inflammation. However, systemic features of the disease would seem to be left untreated. Interestingly, several researchers have observed a "contralateral effect" in animal models of local gene delivery where the delivered transgene is protective not only to the injected joint, but also to distal, untreated joints [12-14]. This effect appears to be independent of trafficking of modified immune cells to distal joints, because ex vivo modified fibroblasts alone are still able to confer a contralateral effect [15]. It is also independent of systemic circulating levels of transgene and non-specific immunosuppression and instead was found to depend on a complex antigen-specific mechanism [16]. Systemic delivery, typically by intravenous administration, would be expected to have a broader therapeutic effect, but is also associated with an increase in side effects and toxicity.

Another consideration for gene transfer is whether to employ in vivo or ex vivo delivery strategies. In vivo strategies have the advantage of being relatively easy and less expensive. In addition, many more studies have been performed in animal models looking at in vivo gene delivery. Ex vivo strategies, although expensive and timeconsuming, have the advantage of being able to treat and select very specific cells, avoiding the possibility that the gene transfer vector could genetically modify a stem cell population and result in oncogene activation. A phase I clinical trial has been performed using a retroviral vector to deliver IL-1 receptor antagonist (IL-1ra) to cultured autologous synovial fibroblasts [17]. The cells were then injected into the RA patients' joints. After a scheduled arthroplasty 1 week later, significant expression of the transgene was seen in the injected joints. No adverse events were reported. This trial was initiated following previous experiments where antagonists of both IL- $1 \beta$ and TNF- $\alpha$ were delivered to autologous cultured rabbit fibroblasts ex vivo and injected into arthritic rabbit knee joints, with significant therapeutic benefit [15, 18].

Most ex vivo studies use fibroblast-like synoviocytes (FLS) as the target cell. These cells have been targeted specifically because they are thought to be directly responsible for cartilage destruction and drive and perpetuate the inflammatory response and autoimmunity [19]. The disadvantages of using this cell type are that FLS have a low proliferation rate, lack highly specific surface markers, and are a non-homogenous population. Future studies may examine other strategies, including gene delivery to $\mathrm{T}$ cells, dendritic cells, muscle cells, or mesenchymal stem cells [20].

\section{Gene transfer vectors}

Gene transfer vectors can be broadly categorized into two groups: viral and non-viral vectors. In general, viral vectors tend to provide for longer-term gene expression but often come with additional safety concerns, ranging from fears of generating replication competent virus during vector production, random insertion of the transgene into the genome following treatment, or development of a harmful immune response.

\section{Plasmid DNA}

The most common non-viral vector used in arthritis studies is plasmid DNA. Plasmid DNA can be delivered by liposomes, gene gun, or direct injection of the plasmid. The use of plasmid DNA tends to be less toxic and less immunogenic than the use of viral vectors and is also easy and relatively inexpensive to produce. However, plasmid DNA often leads to low transfection efficiency and short-term expression of the transgene, lasting only 1-2 weeks [21-23]. These limitations make it unlikely that local delivery of plasmid DNA in the joint will be successful.

The most success with the use of plasmid DNA in gene transfer for arthritis has been garnered through delivery of transgenes to skeletal muscle. Electrotransfer of soluble 
$\mathrm{TNF}-\alpha$ receptor I variants to the tibial-cranial muscle at the onset of collagen-induced arthritis (CIA) led to a decrease in the clinical and histological signs of disease for up to 5 weeks [24]. Similarly, plasmids encoding cDNA for other anti-inflammatory molecules such as IL-1ra and a soluble TNFR-Fc fusion protein have been demonstrated to improve both macroscopic and microscopic scores of CIA when delivered intramuscularly $[25,26]$. Plasmid encoding TGF- $\beta$ delivered to skeletal muscle delayed progression of streptococcal cell wall induced arthritis when administered at the peak of the acute phase and virtually eliminated subsequent inflammation and arthritis when given at the beginning of the chronic phase of the disease [27]. Intramuscular injections of plasmids encoding immunomodulatory molecules such as IL-4, IL-10, viral IL-10, and soluble complement receptor type I have given similar results [28-31]. Intramuscular delivery of a plasmid encoding TIMP-4, and inhibitor of matrix metalloproteinases, completely abolished the development of arthritis in a rat adjuvant-induced arthritis model [32]. Intravenous delivery of a plasmid encoding the heparin-binding domain of fibronectin inhibited leukocyte recruitment and decreased inflammation in CIA [33]. Intra-dermal injection of plasmid encoding IL-10 and intra-peritoneal injection of plasmid IL-10/liposome complexes have also been demonstrated to delay onset and progression of CIA [34, 35]. The liposome delivered DNA was able to maintain expression for only 10 days after injection, significantly less than the intramuscular studies mentioned above. Recently, the use of chitosan, a polycationic polysaccharide derived from crustacean shells, has been shown to act as an efficient gene carrier to rabbit knee joints both in vitro and in vivo [36].

\section{Other non-viral vectors}

Other non-viral gene delivery systems that have potential in the treatment of RA are the artificial chromosome expression (ACE) system and the sleeping beauty (SB) transposon system. The ACE system is attractive because it is nonintegrating and can provide stable and long-term gene expression of one or multiple genes. A feasibility study was recently performed in a Mycobacterium tuberculosis rat arthritis model, which demonstrated that rat skin fibroblasts could be modified ex vivo to express a reporter gene from an artificial chromosome. These cells, when subsequently injected into rat joints, demonstrated engraftment into the synovial tissue microarchitecture and detectable transgene expression. The ACE system did not induce local inflammation at the injection site that is often associated with viral vector administration [37]. The sleeping beauty transposon system melds the advantages of both viral and non-viral vectors, allowing for both integration into the genome and long term expression. No studies have yet been performed in arthritis models using the sleeping beauty transposon system, but success has been found in both cancer and hemophilia models, suggesting that it might be have potential to successfully treat arthritis as well [38].

Viral vectors are by far the most widely used vectors for delivering transgenes in arthritic animal models [39]. There are several different viral vectors that have been examined for use in gene transfer for arthritis, including adenovirus, retrovirus, adeno-associated virus (AAV), and lentivirus, each with their respective advantages and disadvantages.

\section{Adenovirus}

Adenovirus is a non-encapsidated double-stranded DNA virus that can infect non-dividing cells and can be produced at high titers. Many gene-therapy studies have been performed with this vector but it has several limitations that may prevent it from being successful in the clinic. The high prevalence of neutralizing antibodies may prevent successful administration or re-administration. Injected adenovirus also causes a significant inflammatory immune response, which is a safety concern. In addition, adenovirus vectors typically only allow for 1-3 weeks of transgene expression, which would limit its long-term efficacy. Some improvements to adenoviral vectors have recently been made in an effort to improve delivery of transgenes to the synovium. FLS lack the coxsackie-adenovirus receptor (CAR) and are not efficiently transduced by adenovirus. By modifying the fiber knobs on the virus, adenoviral transgene delivery to synoviocytes and synovium was improved dramatically [40, 41]. Other recent improvements include the development of an adenoviral vector with an inflammation inducible promoter [42]. This would allow expression of the transgene during active disease, but expression would turn off once inflammation was brought under control.

\section{Retrovirus}

Retroviruses, mostly derived from the Moloney murine leukemia virus, have a relatively simple genome and structure. They are enveloped viruses and contain two identical copies of their RNA genome. The key feature of the retroviral life cycle is the ability of the RNA genome to be reverse transcribed into double-stranded DNA, which can then randomly integrate into the genome. They have been mostly used in ex vivo studies and are desirable vectors for several reasons. They can provide for long-term stable expression and their integration into the genome makes it possible to permanently correct a genetic defect 
[43]. For arthritis in particular, the inflamed synovium appears to be more susceptible to uptake of the virus [18]. The drawbacks to retroviral vectors are that they only infect non-dividing cells and are produced at low titers. The fact that these vectors integrate into the genome randomly is also a concern. In fact, in a recent clinical trial in France using a retrovirus to correct an X-linked SCID disorder, 3 out of 10 children developed leukemia after the vector inserted in or near a known oncogene. As a result, similar trials in the U.S. for this disorder have been halted until more information can be gathered [44, 45]. Future improvements to these vectors, including the development of self-inactivating vectors, which contain no retroviral promoter or enhancer elements, and use of vectors from non-oncogenic retroviruses will hopefully make them safer for clinical use [43].

\section{Lentivirus}

Lentivirus vectors are derived from retroviral vectors but have the advantage of infecting non-dividing cells. The most commonly studied lentiviral vectors are derived from either human immunodeficiency virus (HIV) or feline immunodeficiency virus (FIV), although equine anemia infectious virus and visna virus have also been examined [38]. The primary concern with HIV vectors is safety. In contrast, FIV is non-pathogenic in humans and does not cause serologic conversion [46]. Using an FIV vector, TNF- $\alpha$ was transduced into primary human FLS with high efficiency. When injected into knees of SCID mice, these cells induced cell proliferation and caused bone and joint destruction [47]. A replication-defective HIV vector encoding endostatin was injected into joints of TNF- $\alpha$ transgenic mice and was shown to decrease synovial blood vessel density and decrease the overall arthritis index [48]. Similarly, intra-articular expression of angiostatin inhibited the progression of CIA in mice [49]. A study examining a VSV-G pseudo-typed HIV vector, which has increased host range and stability, demonstrated that a transgene could be efficiently delivered to the synovium of rat knee joints, with transgene expression lasting up to 6 weeks in immunocompromised animals [50].

\section{AAV}

One of the most promising gene transfer vectors is AAV, which is a small, non-enveloped single-stranded DNA virus with broad tissue tropism. It belongs to the Parvoviridae family and has a $4.68 \mathrm{~kb}$ genome. AAV normally requires adenovirus or herpesvirus to produce active infection. Several serotypes have been identified in primates, with
AAV2 being the prototype for most gene transfer studies. Heparan sulfate proteoglycan has been identified as the primary attachment receptor for AAV, with fibroblast growth factor receptor 1 and integrin $\alpha_{v} \beta_{5}$ acting as coreceptors [51]. Although little is known about the details of AAV infection, some of the basic mechanisms have been described. The virus enters the cell by receptor-mediated endocytosis. Acidification of late endosomes leads to AAV release into the cytosol, with subsequent translocation of the virus to a perinuclear region [52-54]. The virus then enters the nucleus by an unknown mechanism that is independent of the nuclear pore complex [55]. Following uncoating, the single-stranded genome is converted to a double strand and the viral DNA integrates into chromosome 19 (AAVS1 locus) in a site-specific manner [56, 57].

AAV is an attractive vector for gene transfer studies for several reasons. It has been shown to deliver transgenes to a wide variety of tissues, has low immunogenicity, and mediates long-term gene expression [51]. Recombinant, replication incompetent AAV vectors have been designed that lack the Rep genes, which are required for integration, so long-term expression with these vectors is thought to be mediated by episomal viral DNA [58]. In addition, AAV vectors have been designed that are able to package double-stranded viral genomes, bypassing a rate-limiting step of viral transduction (second-strand synthesis) and allowing rapid and highly efficient transduction both in vitro and in vivo [59].

Several studies have demonstrated the efficacy of AAV vectors in arthritis models. Primary and recurrent arthritis were suppressed following a single injection of AAV encoding IL-1ra into knee joints of rats with LPS-induced arthritis. Surprisingly, disease-regulated expression of the transgene was observed [60]. Our laboratory has recently observed a similar phenomenon in in vitro cultured FLS infected with AAV in which inflammatory cytokines can increase transgene expression in these cells in a regulatable, PI3K-dependent manner. Protesosome inhibition has also been shown to enhance AAV transduction of human synoviocytes both in vitro and in vivo [61]. AAV encoding soluble $\mathrm{TNF}-\alpha$ receptor type I decreased synovial cell hyperplasia and cartilage and bone destruction in human $\mathrm{TNF}-\alpha$ transgenic mice injected intra-articularly with the virus [62]. Intra-articular or peri-articular delivery of AAV encoding IL-4 in CIA mice was also shown to decrease paw swelling, protect from cartilage destruction, and delay the onset of CIA [63, 64]. A vIL-10 transgene delivered by AAV under control of a tetracycline inducible promoter decreased the incidence and severity of CIA on a macroscopic, radiologic, and histologic level [65]. More recently, angiostatin, an anti-angiogenic molecule, was demonstrated to efficiently decrease development of CIA in the treated joint when delivered by AAV [66]. 
AAV vectors are in clinical trials for the treatment of cystic fibrosis and hemophilia B and preliminary results are promising [67]. Targeted Genetics Corporation (Seattle, WA) is currently conducting a phase I clinical trial (13G01; identifier NCT00126724) to assess the safety of using an AAV2 vector to deliver a soluble TNF receptor-Fc fusion gene in RA.

\section{Gene transfer strategies}

\section{IL-1 $\beta$ inhibition}

Several gene transfer strategies have been aimed at neutralizing the effects of IL- $1 \beta$. IL- $1 \beta$ communicates with many different cell types in the joint. Its action on these cells leads to emigration of blood cells to the synovium, increased cartilage destruction, and increased production of other chemokines and pro-inflammatory mediators by macrophages, B cells, and T cells [7]. Neutralization of this key cytokine has proven beneficial in the treatment of RA. Several animal models support using gene transfer to block the effects of this cytokine. Primary and recurrent arthritis were suppressed following a single injection of AAV encoding IL-1ra into knee joints of rats with LPS-induced arthritis [60]. Adenoviral vectors encoding IL-1ra proved more effective than soluble type I TNF receptor-IgG fusion protein at reducing cartilage matrix degradation and decreasing leukocyte infiltration into the joint space of rabbits with antigen-induced arthritis [13]. Rabbit synovial fibroblasts modified ex vivo using a retrovirus encoding IL1ra demonstrated a chondroprotective and mild antiinflammatory effect when injected back into the joint after onset of antigen-induced arthritis [18]. This led to a phase I clinical trial using a retroviral vector to deliver IL-1ra to cultured human autologous synovial fibroblasts. The cells were then injected into RA patient joints. After a scheduled arthroplasty 1 week later, significant expression of the transgene was seen in the injected joints, and no adverse events were reported [17].

Intramuscular injection of plasmid DNA encoding IL-1ra has also been shown to decrease paw swelling and arthritis incidence in a CIA mouse model. Reduced synovitis and cartilage erosion were also seen [26, 68]. In a rat model of bacterial cell wall-induced arthritis, rat synoviocytes were modified ex vivo using a retroviral vector to express IL-1ra. When injected into ankle joints prior to reactivation of arthritis, a decreased severity of arthritis and attenuated destruction of cartilage and bone was observed [69]. In a SCID mouse model, human RA FLS transduced with retrovirus encoding IL-1ra co-implanted with normal human cartilage was able prevent progressive cartilage degradation compared to controls [70]. 3T3 mouse fibroblasts transfected with plasmid encoding IL-1ra were able to prevent the onset of CIA and cartilage destruction when injected into knee joints of CIA mice [12]. Similar effects on arthritis were seen in a rabbit model of antigen-induced arthritis in which a retroviral vector carrying the IL-1ra gene was used to transduce rabbit fibroblasts ex vivo, with subsequent injection of the cells into the knee joint [15]. More recently, the soluble form of interleukin-1 receptor accessory protein (sIL-1RAcP) was delivered to CIA mice either using an adenoviral vector or by injection of plasmid transfected $3 \mathrm{~T} 3$ cells. In both instances, a profound prophylactic effect on the development of CIA was observed [71].

\section{TNF- $\alpha$ inhibition}

$\mathrm{TNF}-\alpha$ is another pro-inflammatory cytokine that plays a key role in the pathogenesis of RA. Many of its effects overlap those of IL- $1 \beta$ listed above. Currently, therapies aimed at neutralizing this cytokine represent the most successful treatment strategies for RA. Current regimens involve receiving injections (etanercept) or infusions (infliximab) every 2 or 8 weeks, respectively. Gene transfer strategies have the potential to provide longer-term control and may also be delivered locally rather than systemically, potentially minimizing treatment side effects. Several studies in animal models have been performed. After one injection at onset of CIA, intramuscular electrotransfer of plasmids encoding soluble TNF receptor I variants led to a decrease in clinical and histological signs of CIA [24]. Expression lasted up to 5 weeks and was as least as efficient as repeated injections of the recombinant protein etanercept in controlling the disease. A similar study using a retroviral vector to deliver the transgene peri-articularly saw similar results and also observed a decrease in systemic levels of IgG2a antibodies to collagen type II [72].

Electrotransfer of a plasmid encoding a soluble p75 TNF receptor:Fc fusion protein was also beneficial in a CIA model and was associated with a decrease in the levels of IL- $1 \beta$ and IL-12 in the paw [25]. Other studies using electrotransfer or intramuscular injection of a plasmid with a doxycycline-regulated promoter to control expression of a dimeric soluble TNF receptor II molecule saw a therapeutic effect on CIA only when doxycycline was administered [73, 74]. In TNF- $\alpha$ transgenic mice, intra-articular delivery of soluble TNF receptor I by adeno-associated virus led to a decrease in synovial cell hyperplasia and cartilage and bone destruction [62]. Similarly, AAV5 encoding sTNFRI-Ig was also able to decrease paw swelling in a rat AIA model when expression was under control of an inflammation responsive promoter, but interestingly, not if expression was under control of the CMV promoter [75]. 
Splenocytes from arthritic DBA-1 mice can passively transfer collagen type II-induced arthritis when injected into SCID recipients. If these splenocytes were first modified ex vivo using retroviral vectors to express soluble p75 tumor necrosis factor receptor, the SCID recipients did not develop arthritis, bone erosion, or joint inflammation $[76,77]$. Delivery of a rat TNF receptor:Fc fusion protein in a streptococcal cell wall-induced arthritis model by either plasmid or local or systemic administration of AAV vectors encoding the molecule led to decreased inflammation, pannus formation, bone and joint destruction, and mRNA expression of joint pro-inflammatory cytokines [21]. Adenoviral delivery of a soluble TNF receptor type I-IgG fusion protein directly to rabbit knees with antigen-induced arthritis reduced-cartilage matrix degradation and decreased leukocyte infiltration into the joint space, especially when administered in conjunction with a soluble IL-1 type I receptor-IgG fusion protein [13]. The above animal model data has led to the initiation of a phase I clinical trial using AAV vectors to deliver soluble TNF Receptor:Fc fusion protein (Targeted Genetics Corporation).

\section{IL-18 inhibition}

IL-18 is a pro-inflammatory cytokine that is overexpressed in the synovium of RA patients and correlates with inflammation. Elevated levels of this cytokine are also observed in serum and synovial fluid. Overexpression of an IL-18-binding protein using an adenoviral vector was able to ameliorate arthritis in a CIA model, indicating neutralization of IL-18 may be an effective target in the future treatment of RA [78].

\section{Immune deviation}

Previously, an imbalance between Th1 and Th2 cytokines was thought to play a role in the pathogenesis of several inflammatory diseases, including RA. Th1 cells secrete cytokines like IFN- $\gamma$ that promote a pro-inflammatory environment, while Th2 cytokines secrete cytokines like IL-4, IL-10, and IL-13 that down-regulate Th1 activity. It was previously felt that overproduction of Th1 cytokines contributed significantly to the pathogenesis of RA. More recently, a new subset of T cells, termed Th17 cells, have been identified [79]. These cells produce, among other cytokines, IL-17, a pro-inflammatory cytokine previously implicated in the pathogenesis of CIA [80]. Dysregulation of Th17 cells and IL-17 overproduction has been implicated in the pathogenesis of inflammatory diseases and the development of severe autoimmunity. In fact, the pathogenesis of RA may be more directly related to an imbalance between Th17 cells and Foxp3-positive regulatory $\mathrm{T}$ cells than an imbalance between $\mathrm{Th} 1$ and $\mathrm{Th} 2$ cells [81]. Regardless of the exact mechanism, several strategies aimed at immune deviation have been successful in animal models of arthritis and are outlined below.

IL-13 inhibits activated monocytes/macrophages from secreting a variety of pro-inflammatory molecules. A possible role for this cytokine in the pathogenesis of RA was observed when adenoviral delivery of IL-13 to RA synovial tissues explants led to a decrease in IL- $1 \beta$, TNF- $\alpha$, IL-8, MCP-1, NAP-78, PGE 2 , and MIP- $1 \alpha$ when compared to controls [82]. Subsequent studies demonstrated that adenoviral delivery of IL-13 directly to ankle joints in a rat antigen-induced arthritis model significantly decreased paw size, bony destruction, vascularization, inflammatory cell infiltration, and inflammatory cytokine production [83]. IL-13 overexpression during immune-complex-mediated arthritis significantly decreased chondrocyte death and MMP mediated cartilage destruction, despite the presence of enhanced inflammation [84].

Using IL-4 to skew the cytokine profile towards Th2, or perhaps by inhibiting Th17 cell production, has also proven successful. Adenoviral delivery of IL-4 to RA synovial tissue explants demonstrated decrease IL- $1 \beta$, TNF- $\alpha$, IL- 8 , MCP1 , and $\mathrm{PGE}_{2}$ in the cultured medium [85]. Intra-articular delivery of adenoviral vectors encoding IL-4 to CIA mice led to an enhanced onset of inflammation but less chondrocyte death and cartilage and bone erosion. Proteoglycan synthesis was enhanced and there was decreased MMP activity [86]. IL-17, IL-12, cathepsin K and osteoprotegrin ligand mRNA levels were also reduced [86, 87]. Kim et al. observed similar effects on CIA upon local and systemic administration of adenoviral vectors encoding IL-4 [88]. AAV-mediated delivery of IL-4 has also prove beneficial in CIA models [63, 64]. Electrotransfer of an IL-4 encoding plasmid prior to CIA onset decreased synovitis and cartilage destruction, with an associated decrease in IL- $1 \beta$ in the paw and an increased TIMP2:MMP2 ratio [29]. Similar results were also seen using either gene gun delivery or intra-dermal administration of plasmid encoding IL-4 [89]. Both retroviral and adenoviral delivery of IL-4 in a rat antigen-induced arthritis model had beneficial effects [90-92]. Cell-based therapies that deliver IL-4 in arthritis models have also been successful. Injection of fibroblast transfected with plasmid encoding IL-4 decreased histologic evidence of joint inflammation and destruction in a CIA model $[93,94]$. Likewise, collagen type II pulsed antigen presenting cells engineered to secret IL-4 down-regulated CIA [95].

IL-10 is an anti-inflammatory cytokine that has demonstrated benefit in several animal models of RA. Either intramuscular administration via electrotransfer or intradermal injection of plasmid encoding IL-10 had beneficial effects on CIA [31, 35]. Similarly, systemic administration 
of a plasmid IL-10/liposome mixture decreased signs of CIA after a single intra-peritoneal injection [34]. Viral IL10 (vIL-10) is homologous to human and mouse IL-10 but while retaining its immunosuppressive function, it lacks many of the immunostimulatory properties of IL-10, and therefore may be a superior treatment option. An adenoviral vector encoding vIL-10 was able to decrease CIA when delivered locally or systemically [14, 96, 97]. Electrotransfer of viral IL-10 decreased histologic evidence of arthritis in an arthrogen collagen-induced arthritis model and was associated with decreased TNF- $\alpha$, IL- $1 \beta$, and IL-6 transcripts in the joint [30]. A tet-inducible vIL-10 transgene delivered by AAV was able to decrease macroscopic, radiology, and histologic signs of CIA only when doxycycline was administered [65].

TGF- $\beta$ is a pleiotropic cytokine with many different effects on many different cell types and has been suggested of playing a role in RA. While some of its effects, like immunosuppression, would appear to be beneficial for RA, it has also been associated with pro-inflammatory activity. Not surprisingly, data from animal models using gene transfer support both possibilities, making its true role in RA difficult to decipher. Splenocytes from CIA mice were isolated and infected ex vivo with a retroviral vector encoding TGF- $\beta$. These cells were then injected in the intra-peritoneal cavity 5 days after arthritis onset. Without TGF- $\beta$ expression, an exacerbation of arthritis is normally observed. However, TGF- $\beta$ expressing splenocytes were able to inhibit this exacerbation and also resulted in a decrease in MMP2 activity and a transient reduction in anti-collagen type II antibodies [98]. In a rat streptococcal cell wall-induced arthritis model, intramuscular delivery of plasmid encoding TGF- $\beta$ showed significant decreases in inflammatory cell infiltration, pannus formation, bone and joint destruction, and inflammatory cytokine production [27]. In contrast to the above reports, another study found that injection of adenovirus encoding TGF- $\beta$ into the knees of rabbits with antigen-induced arthritis resulted in significant pathology in the knee joint and surrounding tissue, suggesting that TGF- $\beta$ therapy may not be suitable for treating arthritis in some models [99].

CTLA-4Ig fusion protein binds to the co-stimulatory molecules B7-1 and B7-2 present on antigen-presenting cells and blocks CD28/B7 interactions, resulting in decreased $\mathrm{T}$ cell activation. It has been shown to ameliorate several experimental autoimmune diseases, including CIA. A single intravenous injection of an adenovirus encoding CTLA-4Ig fusion protein suppressed established CIA as least as efficiently as repeated injections of monoclonal antibody to CTLA-4. Pathogenic cellular and humoral responses were also diminished in adenoviral vector treated group as compared to antibody treated and control groups [100]. CIA could also be inhibited both histologically and clinically by intra-articular administration of a low dose of adenovirus encoding CTLA-4Ig fusion protein [101].

\section{Promoting apoptosis}

One of the key features of RA is the increased cellularity of the synovial lining leading to pannus formation, which has been shown to contribute to cartilage invasiveness and bone destruction. Promoting synovial apoptosis has been suggested as a treatment strategy for RA. In a rabbit model of arthritis, intra-articular adenoviral delivery of TNF-related apoptosis-inducing ligand (TRAIL) was able to increase apoptosis in the synovial cell lining, decrease inflammatory cell infiltration, and promote new matrix deposition [102]. Mice injected with collagen type II-pulsed antigen presenting cells engineered to express TRAIL under control of a doxycycline inducible promoter decreased the incidence of CIA and infiltration of T cells in the joint in the presence of doxycycline. In situ TUNEL staining demonstrated TRAILinduced apoptosis of activated T cells in the spleen [103]. Modulation of TRAIL receptor expression on RA synoviocytes has also been suggested as a gene therapy strategy for the treatment of RA [104].

Injection of adenovirus-expressing Fas ligand (FasL) into joints of CIA mice induced apoptosis and ameliorated CIA. IFN- $\gamma$ production by collagen-specific $\mathrm{T}$ cells was also reduced [105]. Ex vivo modified T cells engineered to express FasL were injected into human RA synovial tissue that had been implanted in SCID mice. Analysis of the tissue following treatment demonstrated that synoviocytes and mononuclear cells present in the tissue had been eliminated by apoptosis through a Fas/FasL interaction [106]. Similar results were observed when adenovirus encoding FasL was injected directly into the implanted tissue [107]. Dendritic cells modified by adenoviral vectors to express FasL were able to suppress CIA when systemically injected and also demonstrated decreased IFN- $\gamma$ production from spleen-derived lymphocytes and decreased $\mathrm{T}$-cell proliferation in response to collagen stimulation [108]. Fas-associated death domain protein (FADD) also plays a key role in Fas-mediated apoptosis of synovial cells. It was found that adenoviral vectors expressing FADD could induce apoptosis in synoviocytes both in vitro and in vivo, suggesting that this strategy may be effective in the treatment of RA [109].

\section{Anti-angiogenesis}

Increased cellularity of the synovial lining is also associated with neo-vascularization in the local environment of the joint. This angiogenesis is necessary for the development 
and maintenance of the pannus and also provides nutrients required for the survival and proliferation of infiltrating inflammatory cells $[110,111]$. A peptide targeted to the integrins present in the inflamed synovium and associated with angiogenesis was fused to an anti-apoptotic peptide. Systemic administration of this fusion peptide in a CIA model resulted in decreased clinical arthritis and increased apoptosis of synovial blood vessels [112]. 3T3 fibroblasts modified with retroviral vectors to express angiostatin were able to decrease pannus formation and cartilage erosion when injected into knee joints of mice with CIA. Arthritisassociated angiogenesis was also inhibited [113]. AAV and HIV vector-mediated delivery of angiostatin to CIA knee joints were similarly beneficial $[49,66]$. The potent antiangiogenic factor endostatin was able to decrease arthritis and reduce blood vessel density in a human TNF-transgenic mouse model of arthritis when delivered to knee joints using a lentiviral vector [48]. Tie2 has also been demonstrated to play a role in angiogenesis in arthritis. Adenoviral delivery of a soluble receptor for Tie2 resulted in a decreased incidence and severity of CIA, inhibition of angiogenesis, and was associated with decreased bone destruction that appeared to result from a decrease in RANKL [114]. VEGF is another angiogenic factor that promotes synovitis and bone destruction in arthritis. When soluble VEGF receptor I was administered via adenoviral vectors to CIA mice, disease activity was suppressed significantly [115]. Thrombospondins (TSP1 and 2) have also been shown to inhibit angiogenesis and also decrease proinflammatory cytokine production in animal models of arthritis [116, 117]. In addition, adenoviral gene transfer of a urokinase plasminogen inhibitor was also able to inhibit angiogenesis in a CIA model [118].

Targeting matrix degradation enzymes

Matrix metalloproteinases (MMPs) degrade extracellular matrix components and have been demonstrated to contribute to cartilage degradation in RA. Ribozymes and an antisense construct targeting the destruction of MMP-1 delivered to RA synovial fibroblasts via retroviral vectors decreased MMP-1 production and reduced the invasiveness of RA synovial fibroblasts in a SCID mouse model of RA, suggesting that this may be an effective approach to inhibiting cartilage destruction in RA [119, 120]. Another strategy that has proven successful is to increase the ratio of tissue inhibitors of matrix metalloproteinases (TIMPs) to MMPs. In a rat antigen-induced arthritis model, intramuscular injection of naked DNA encoding TIMP-4 completely abolished the development of the disease [32]. Likewise, adenoviral delivery of TIMP-1 and TIMP-3 to RA synovial fibroblasts significantly decreased their invasiveness both in vitro and in an in vivo SCID mouse model of RA. These molecules were found to act by both decreasing MMP production and reducing cell proliferation [121].

\section{Targeting NF $\kappa \mathrm{B}$}

The transcription factor $\mathrm{NF} \kappa \mathrm{B}$ plays a significant role in the activation of many cytokines that contribute to the pathogenesis of RA. Inhibition of this factor could lead to therapeutic benefit in RA. Injection of decoy oligodeoxynucleotides with high affinity for NFkB into ankle joints of CIA rats significantly decreased joint swelling and joint destruction. The levels of the pro-inflammatory cytokines TNF- $\alpha$ and IL- $1 \beta$ were also decreased in the treated joints [122]. Another group found that inhibiting $\mathrm{NF} \kappa \mathrm{B}$ in RA synovial fibroblasts using an adenovirus to deliver a dominant negative inhibitor of $\mathrm{NF} \kappa \mathrm{B}$ led to an increase in apoptosis upon stimulation with TNF- $\alpha$. These cells are normally resistant to apoptosis when stimulated with TNF$\alpha$, suggesting that this strategy may be beneficial in the treatment of RA [123]. In adjuvant arthritis in rats, a dominant negative IkB kinase $\beta$ (IKK $\beta$ ) was used to inhibit the $\mathrm{NF} \kappa \mathrm{B}$ pathway. Delivering the molecule intra-articularly using an AAV5 vector resulted in significantly reduced paw swelling and decreased levels of IL-6 and TNF- $\alpha$. Bone and cartilage destruction, as well as MMP-3 and TIMP-1 levels were unaffected. The same vector was also able to efficiently transduce ex vivo-cultured biopsies from joints of human RA patients. TNF- $\alpha$-induced IL-6 production was significantly decreased in the ex vivo cultures receiving the vector encoding IKK $\beta$ [124].

\section{Other strategies}

Other molecules that have been demonstrated to play a role in arthritis using gene transfer in various in vitro or animal models are Csk, cathepsin L, fibronectin, galectin-1, p16 ${ }^{\mathrm{INK} 4 \mathrm{~A}}, \mathrm{p} 21^{\mathrm{Cip} 1}$, SOCS3, soluble CR1, superoxide dismutase and catalase, Ras, and prothymosin $\alpha[28,33$, 125-136]. Vectors and genes used to successfully treat animal models of arthritis are summarized in Table 1.

\section{Safety concerns}

As with most investigative therapies, one of the most important concerns with regards to gene transfer technologies is the issue of safety. While the FDA has outlined specific strict standards for clinical trial protocols for gene transfer studies, there have been several instances where 


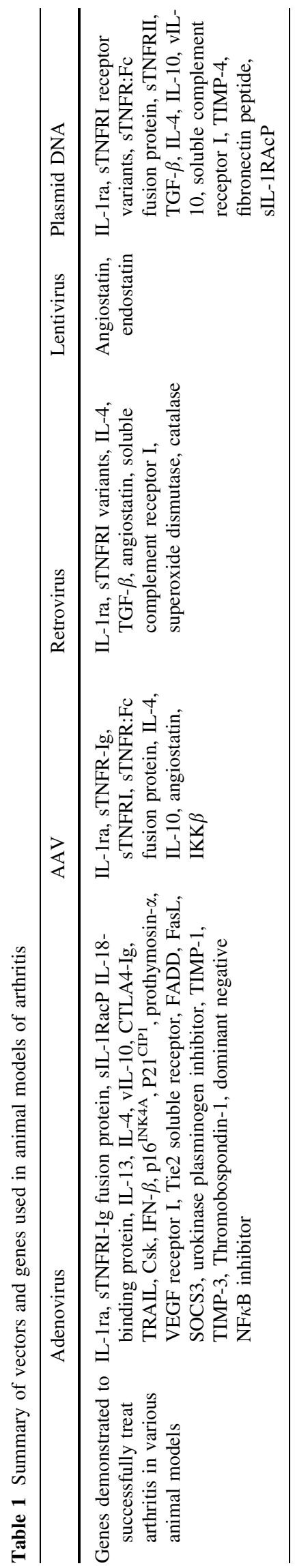

the therapy has resulted in serious adverse events in patients enrolled in the studies. The most widely known is probably the September 1999 death of Jesse Gelsinger, who had a fatal systemic inflammatory response to adenoviral vector gene transfer [137]. Retroviral vectors have also resulted in insertional mutagenesis leading to a secondary malignancy [44]. Lentiviral vectors may have this potential as well as sharing a similar mechanism, although this has never been demonstrated in clinical studies. More recently, in July of 2007, Jolee Mohr, a patient enrolled in Targeted Genetics' clinical trial for rheumatoid arthritis using AAV vectors, died several weeks following her second injection of the experimental treatment. The trial is currently suspended, and although the investigation into her death is still ongoing, initial results suggest she died of a systemic fungal infection that may be unrelated to the injected virus. This case and the final results of the investigation are likely to have a large impact on the future of gene therapy trials in the United States, as AAV has been heralded as one of the most promising vectors in the field, precisely because it has, until now, failed to reveal significant safety concerns in previous studies.

\section{Future of gene therapy for arthritis}

Much progress has been made in the past several years in the use of gene therapy for the treatment of arthritis. However, there are many obstacles that must be overcome in order for it to become a viable treatment option. Future studies will need to address improving targeted delivery of vectors, regulating transgene expression, obtaining longterm transgene expression, and improving the safety and efficacy of the vectors already in use before gene therapy becomes a viable clinical therapy for arthritis.

Even in light of the recent setback in clinical trials utilizing AAV vectors, the authors believe that the future of gene transfer for arthritis will rely heavily upon this vector. Once the safety issues have been clarified, these trials can hopefully move forward. Presently, AAV would seem to be the viral vector that has the best profile in terms of safety, efficacy, and level and length of transgene expression. Alternatively, strategies using siRNA technology or preventing the dysregulation of Th17 cells would appear to be emerging as treatment strategies that may one day outperform the current standards of care for rheumatoid arthritis.

\section{References}

1. Alamanos Y, Drosos AA. Epidemiology of adult rheumatoid arthritis. Autoimmun Rev 2005;4(3):130-6.

2. Pollard L, Choy EH, Scott DL. The consequences of rheumatoid arthritis: quality of life measures in the individual patient. Clin Exp Rheumatol 2005;23 5 Suppl 39:S43-52. 
3. Fautrel B, Guillemin F. Cost of illness studies in rheumatic diseases. Curr Opin Rheumatol 2002;14(2):121-6.

4. Firestein GS. Evolving concepts of rheumatoid arthritis. Nature 2003;423(6937):356-61.

5. Weyand CM. New insights into the pathogenesis of rheumatoid arthritis. Rheumatology (Oxford) 2000;39 Suppl 1:3-8.

6. Goldring SR. Pathogenesis of bone and cartilage destruction in rheumatoid arthritis. Rheumatology (Oxford) 2003;42 Suppl 2:ii11-6.

7. Kay J, Calabrese L. The role of interleukin-1 in the pathogenesis of rheumatoid arthritis. Rheumatology (Oxford) 2004;43 Suppl 3:iii2-9.

8. Dayer JM. The pivotal role of interleukin-1 in the clinical manifestations of rheumatoid arthritis. Rheumatology (Oxford) 2003;42 Suppl 2:ii3-10.

9. Koch AE, Kunkel SL, Strieter RM. Cytokines in rheumatoid arthritis. J Investig Med 1995;43(1):28-38.

10. Smolen JS, Steiner G. Therapeutic strategies for rheumatoid arthritis. Nat Rev Drug Discov 2003;2(6):473-88.

11. Olsen NJ, Stein CM. New drugs for rheumatoid arthritis. N Engl J Med 2004;350(21):2167-79.

12. Bakker AC, Joosten LA, Arntz OJ, Helsen MM, Bendele AM, van de Loo FA, et al. Prevention of murine collagen-induced arthritis in the knee and ipsilateral paw by local expression of human interleukin-1 receptor antagonist protein in the knee. Arthritis Rheum 1997;40(5):893-900.

13. Ghivizzani SC, Lechman ER, Kang R, Tio C, Kolls J, Evans $\mathrm{CH}$, et al. Direct adenovirus-mediated gene transfer of interleukin 1 and tumor necrosis factor alpha soluble receptors to rabbit knees with experimental arthritis has local and distal antiarthritic effects. Proc Natl Acad Sci USA 1998;95(8):4613-8.

14. Ma Y, Thornton S, Duwel LE, Boivin GP, Giannini EH, Leiden $\mathrm{JM}$, et al. Inhibition of collagen-induced arthritis in mice by viral IL-10 gene transfer. J Immunol 1998;161(3):1516-24.

15. Kim SH, Lechman ER, Kim S, Nash J, Oligino TJ, Robbins PD. Ex vivo gene delivery of IL-1Ra and soluble TNF receptor confers a distal synergistic therapeutic effect in antigen-induced arthritis. Mol Ther 2002;6(5):591-600.

16. Lechman ER, Keravala A, Nash J, Kim SH, Mi Z, Robbins PD. The contralateral effect conferred by intra-articular adenovirusmediated gene transfer of viral IL-10 is specific to the immunizing antigen. Gene Ther 2003;10(24):2029-35.

17. Evans CH, Robbins PD, Ghivizzani SC, Wasko MC, Tomaino MM, Kang R, et al. Gene transfer to human joints: progress toward a gene therapy of arthritis. Proc Natl Acad Sci USA 2005;102(24):8698-703.

18. Otani K, Nita I, Macaulay W, Georgescu HI, Robbins PD, Evans $\mathrm{CH}$. Suppression of antigen-induced arthritis in rabbits by ex vivo gene therapy. J Immunol 1996;156(9):3558-62.

19. Mor A, Abramson SB, Pillinger MH. The fibroblast-like synovial cell in rheumatoid arthritis: a key player in inflammation and joint destruction. Clin Immunol 2005;115(2):118-28.

20. Pap T, Gay RE, Muller-Ladner U, Gay S. Ex vivo gene transfer in the years to come. Arthritis Res 2002;4(1):10-2.

21. Chan JM, Villarreal G, Jin WW, Stepan T, Burstein H, Wahl SM. Intraarticular gene transfer of TNFR:Fc suppresses experimental arthritis with reduced systemic distribution of the gene product. Mol Ther 2002;6(6):727-36.

22. Ohashi S, Kubo T, Kishida T, Ikeda T, Takahashi K, Arai Y, et al. Successful genetic transduction in vivo into synovium by means of electroporation. Biochem Biophys Res Commun 2002;293(5):1530-5.

23. Yovandich J, O'Malley B Jr, Sikes M, Ledley FD. Gene transfer to synovial cells by intra-articular administration of plasmid DNA. Hum Gene Ther 1995;6(5):603-10.
24. Bloquel C, Bessis N, Boissier MC, Scherman D, Bigey P. Gene therapy of collagen-induced arthritis by electrotransfer of human tumor necrosis factor-alpha soluble receptor I variants. Hum Gene Ther 2004;15(2):189-201.

25. Kim JM, Ho SH, Hahn W, Jeong JG, Park EJ, Lee HJ, et al. Electro-gene therapy of collagen-induced arthritis by using an expression plasmid for the soluble p75 tumor necrosis factor receptor-Fc fusion protein. Gene Ther 2003;10(15):1216-24.

26. Kim JM, Jeong JG, Ho SH, Hahn W, Park EJ, Kim S, et al. Protection against collagen-induced arthritis by intramuscular gene therapy with an expression plasmid for the interleukin-1 receptor antagonist. Gene Ther 2003;10(18):1543-50.

27. Song XY, Gu M, Jin WW, Klinman DM, Wahl SM. Plasmid DNA encoding transforming growth factor-betal suppresses chronic disease in a streptococcal cell wall-induced arthritis model. J Clin Invest 1998;101(12):2615-21.

28. Dreja H, Annenkov A, Chernajovsky Y. Soluble complement receptor 1 (CD35) delivered by retrovirally infected syngeneic cells or by naked DNA injection prevents the progression of collagen-induced arthritis. Arthritis Rheum 2000;43(8):1698709.

29. Ho SH, Hahn W, Lee HJ, Kim DS, Jeong JG, Kim S, et al. Protection against collagen-induced arthritis by electrotransfer of an expression plasmid for the interleukin-4. Biochem Biophys Res Commun 2004;321(4):759-66.

30. Kuroda T, Maruyama H, Shimotori M, Higuchi N, Kameda S, Tahara $\mathrm{H}$, et al. Effects of viral interleukin 10 introduced by in vivo electroporation on arthrogen-induced arthritis in mice. J Rheumatol 2006;33(3):455-62.

31. Saidenberg-Kermanac'h N, Bessis N, Deleuze V, Bloquel C, Bureau M, Scherman D, et al. Efficacy of interleukin-10 gene electrotransfer into skeletal muscle in mice with collageninduced arthritis. J Gene Med 2003;5(2):164-71.

32. Celiker MY, Ramamurthy N, Xu JW, Wang M, Jiang Y, Greenwald R, et al. Inhibition of adjuvant-induced arthritis by systemic tissue inhibitor of metalloproteinases 4 gene delivery. Arthritis Rheum 2002;46(12):3361-8.

33. Imagawa $T$, Watanabe S, Katakura S, Boivin GP, Hirsch R. Gene transfer of a fibronectin peptide inhibits leukocyte recruitment and suppresses inflammation in mouse collageninduced arthritis. Arthritis Rheum 2002;46(4):1102-8.

34. Fellowes R, Etheridge CJ, Coade S, Cooper RG, Stewart L, Miller AD, et al. Amelioration of established collagen induced arthritis by systemic IL-10 gene delivery. Gene Ther 2000;7(11):967-77.

35. Miyata M, Sasajima T, Sato H, Saito A, Saito A, Iriswa A, et al. Suppression of collagen induced arthritis in mice utilizing plasmid DNA encoding interleukin 10. J Rheumatol 2000;27(7):1601-5.

36. Zhang X, Yu C, Xushi,Zhang C, Tang T, Dai K. Direct chitosanmediated gene delivery to the rabbit knee joints in vitro and in vivo. Biochem Biophys Res Commun 2006;341(1):202-8.

37. Adriaansen J, Vervoordeldonk MJ, Vanderbyl S, de Jong G, Tak PP. A novel approach for gene therapy: engraftment of fibroblasts containing the artificial chromosome expression system at the site of inflammation. J Gene Med 2006;8(1):63-71.

38. Barquinero J, Eixarch H, Perez-Melgosa M. Retroviral vectors: new applications for an old tool. Gene Ther 2004;11 Suppl $1:$ S3-9.

39. Nita I, Ghivizzani SC, Galea-Lauri J, Bandara G, Georgescu HI, Robbins PD, et al. Direct gene delivery to synovium. An evaluation of potential vectors in vitro and in vivo. Arthritis Rheum 1996;39(5):820-8.

40. Goossens PH, Havenga MJ, Pieterman E, Lemckert AA, Breedveld FC, Bout A, et al. Infection efficiency of type 5 
adenoviral vectors in synovial tissue can be enhanced with a type 16 fiber. Arthritis Rheum 2001;44(3):570-7.

41. Toh ML, Hong SS, van de Loo F, Franqueville L, Lindholm L, van den Berg W, et al. Enhancement of adenovirus-mediated gene delivery to rheumatoid arthritis synoviocytes and synovium by fiber modifications: role of arginine-glycine-aspartic acid (RGD)- and non-RGD-binding integrins. J Immunol 2005;175(11):7687-98.

42. van de Loo FA, de Hooge AS, Smeets RL, Bakker AC, Bennink $\mathrm{MB}$, Arntz OJ, et al. An inflammation-inducible adenoviral expression system for local treatment of the arthritic joint. Gene Ther 2004;11(7):581-90.

43. Anson DS. The use of retroviral vectors for gene therapy-what are the risks? A review of retroviral pathogenesis and its relevance to retroviral vector-mediated gene delivery. Genet Vaccines Ther 2004;2(1):9.

44. Hacein-Bey-Abina S, Von Kalle C, Schmidt M, McCormack MP, Wulffraat N, Leboulch P, et al. LMO2-associated clonal T cell proliferation in two patients after gene therapy for SCIDX1. Science 2003;302(5644):415-9.

45. Kaiser J. Gene therapy. Panel urges limits on X-SCID trials. Science 2005;307(5715):1544-5.

46. Sauter SL, Gasmi M. FIV vector systems. Somat Cell Mol Genet 2001;26(1-6):99-129.

47. Lin YL, Noel D, Mettling C, Reant B, Clot J, Jorgensen C, et al. Feline immunodeficiency virus vectors for efficient transduction of primary human synoviocytes: application to an original model of rheumatoid arthritis. Hum Gene Ther 2004;15(6):58896.

48. Yin G, Liu W, An P, Li P, Ding I, Planelles V, et al. Endostatin gene transfer inhibits joint angiogenesis and pannus formation in inflammatory arthritis. Mol Ther 2002;5(5 Pt 1):547-54.

49. Kato K, Miyake K, Igarashi T, Yoshino S, Shimada T. Human immunodeficiency virus vector-mediated intra-articular expression of angiostatin inhibits progression of collagen-induced arthritis in mice. Rheumatol Int 2005;25(7):522-9.

50. Gouze E, Pawliuk R, Pilapil C, Gouze JN, Fleet C, Palmer GD, et al. In vivo gene delivery to synovium by lentiviral vectors. Mol Ther 2002;5(4):397-404.

51. Lai CM, Lai YK, Rakoczy PE. Adenovirus and adeno-associated virus vectors. DNA Cell Biol 2002;21(12):895-913.

52. Bartlett JS, Wilcher R, Samulski RJ. Infectious entry pathway of adeno-associated virus and adeno-associated virus vectors. J Virol 2000;74(6):2777-85.

53. Douar AM, Poulard K, Stockholm D, Danos O. Intracellular trafficking of adeno-associated virus vectors: routing to the late endosomal compartment and proteasome degradation. J Virol 2001;75(4):1824-33.

54. Sanlioglu AD, Karacay B, Benson PK, Engelhardt JF, Sanlioglu S. Novel approaches to augment adeno-associated virus type-2 endocytosis and transduction. Virus Res 2004;104(1): $51-9$.

55. Hansen J, Qing K, Srivastava A. Infection of purified nuclei by adeno-associated virus 2. Mol Ther 2001;4(4):289-96.

56. Ferrari FK, Samulski T, Shenk T, Samulski RJ. Second-strand synthesis is a rate-limiting step for efficient transduction by recombinant adeno-associated virus vectors. J Virol 1996;70(5): 3227-34.

57. Fisher KJ, Gao GP, Weitzman MD, DeMatteo R, Burda JF, Wilson JM. Transduction with recombinant adeno-associated virus for gene therapy is limited by leading-strand synthesis. J Virol 1996;70(1):520-32.

58. Ponnazhagan S, Erikson D, Kearns WG, Zhou SZ, Nahreini P, Wang XS, et al. Lack of site-specific integration of the recombinant adeno-associated virus 2 genomes in human cells. Hum Gene Ther 1997;8(3):275-84.
59. Wang Z, Ma HI, Li J, Sun L, Zhang J, Xiao X. Rapid and highly efficient transduction by double-stranded adeno-associated virus vectors in vitro and in vivo. Gene Ther 2003;10(26):2105-11.

60. Pan RY, Chen SL, Xiao X, Liu DW, Peng HJ, Tsao YP. Therapy and prevention of arthritis by recombinant adeno-associated virus vector with delivery of interleukin-1 receptor antagonist. Arthritis Rheum 2000;43(2):289-97.

61. Jennings K, Miyamae T, Traister R, Marinov A, Katakura S, Sowders D, et al. Proteasome inhibition enhances AAV-mediated transgene expression in human synoviocytes in vitro and in vivo. Mol Ther 2005;11(4):600-7.

62. Zhang HG, Xie J, Yang P, Wang Y, Xu L, Liu D, et al. Adenoassociated virus production of soluble tumor necrosis factor receptor neutralizes tumor necrosis factor alpha and reduces arthritis. Hum Gene Ther 2000;11(17):2431-42.

63. Cottard V, Mulleman D, Bouille P, Mezzina M, Boissier MC, Bessis N. Adeno-associated virus-mediated delivery of IL-4 prevents collagen-induced arthritis. Gene Ther 2000;7(22): 1930-9.

64. Watanabe S, Imagawa T, Boivin GP, Gao G, Wilson JM, Hirsch R. Adeno-associated virus mediates long-term gene transfer and delivery of chondroprotective IL-4 to murine synovium. Mol Ther 2000;2(2):147-52.

65. Apparailly F, Millet V, Noel D, Jacquet C, Sany J, Jorgensen C. Tetracycline-inducible interleukin-10 gene transfer mediated by an adeno-associated virus: application to experimental arthritis. Hum Gene Ther 2002;13(10):1179-88.

66. Takahashi H, Kato K, Miyake K, Hirai Y, Yoshino S, Shimada $\mathrm{T}$. Adeno-associated virus vector-mediated anti-angiogenic gene therapy for collagen-induced arthritis in mice. Clin Exp Rheumatol 2005;23(4):455-61.

67. Conlon TJ, Flotte TR. Recombinant adeno-associated virus vectors for gene therapy. Expert Opin Biol Ther 2004;4(7): 1093-101.

68. Jeong JG, Kim JM, Ho SH, Hahn W, Yu SS,Kim S. Electrotransfer of human IL-1Ra into skeletal muscles reduces the incidence of murine collagen-induced arthritis. J Gene Med 2004;6(10):1125-33.

69. Makarov SS, Olsen JC, Johnston WN, Anderle SK, Brown RR, Baldwin AS Jr, et al. Suppression of experimental arthritis by gene transfer of interleukin 1 receptor antagonist cDNA. Proc Natl Acad Sci USA 1996;93(1):402-6.

70. Muller-Ladner U, Roberts CR, Franklin BN, Gay RE, Robbins PD, Evans $\mathrm{CH}$, et al. Human IL-1Ra gene transfer into human synovial fibroblasts is chondroprotective. J Immunol 1997;158(7): 3492-8.

71. Smeets RL, van de Loo FA, Joosten LA, Arntz OJ, Bennink MB, Loesberg WA, et al. Effectiveness of the soluble form of the interleukin-1 receptor accessory protein as an inhibitor of interleukin-1 in collagen-induced arthritis. Arthritis Rheum 2003;48(10):2949-58.

72. Mukherjee P, Wu B, Mayton L, Kim SH, Robbins PD, Wooley $\mathrm{PH}$. TNF receptor gene therapy results in suppression of IgG2a anticollagen antibody in collagen induced arthritis. Ann Rheum Dis 2003;62(8):707-14.

73. Gould DJ, Bright C, Chernajovsky Y. Inhibition of established collagen-induced arthritis with a tumour necrosis factor-alpha inhibitor expressed from a self-contained doxycycline-regulated plasmid. Arthritis Res Ther 2004;6(2):R103-13.

74. Gould D, Yousaf N, Fatah R, Subang MC, Chernajovsky Y. Gene therapy with an improved doxycycline-regulated plasmid encoding a tumour necrosis factor-alpha inhibitor in experimental arthritis. Arthritis Res Ther 2007;9(1):R7.

75. Adriaansen J, Khoury M, de Cortie CJ, Fallaux FJ, Bigey P, Scherman D, et al. Reduction of arthritis following intra-articular administration of an adeno-associated virus serotype 5 
expressing a disease-inducible TNF-blocking agent. Ann Rheum Dis 2007.

76. Chernajovsky Y, Adams G, Podhajcer OL, Mueller GM, Robbins PD, Feldmann M. Inhibition of transfer of collagen-induced arthritis into SCID mice by ex vivo infection of spleen cells with retroviruses expressing soluble tumor necrosis factor receptor. Gene Ther 1995;2(10):731-5.

77. Mageed RA, Adams G, Woodrow D, Podhajcer OL, Chernajovsky Y. Prevention of collagen-induced arthritis by gene delivery of soluble p75 tumour necrosis factor receptor. Gene Ther 1998;5(12):1584-92.

78. Smeets RL, van de Loo FA, Arntz OJ, Bennink MB, Joosten LA, van den Berg WB. Adenoviral delivery of IL-18-binding protein $\mathrm{C}$ ameliorates collagen-induced arthritis in mice. Gene Ther 2003;10(12):1004-11.

79. Harrington LE, Hatton RD, Mangan PR, Turner H, Murphy TL, Murphy KM, et al. Interleukin 17-producing CD4+ effector T cells develop via a lineage distinct from the T helper type 1 and 2 lineages. Nat Immunol 2005;6(11):1123-32.

80. Lubberts E, Koenders MI, Oppers-Walgreen B, van den Bersselaar L, Coenen-de Roo CJ, Joosten LA, et al. Treatment with a neutralizing anti-murine interleukin-17 antibody after the onset of collagen-induced arthritis reduces joint inflammation, cartilage destruction, and bone erosion. Arthritis Rheum 2004;50(2):650-9.

81. Bettelli E, Carrier Y, Gao W, Korn T, Strom TB, Oukka M, et al. Reciprocal developmental pathways for the generation of pathogenic effector TH17 and regulatory T cells. Nature 2006;441(7090):235-8.

82. Woods JM, Katschke KJ Jr, Tokuhira M, Kurata H, Arai KI, Campbell PL, et al. Reduction of inflammatory cytokines and prostaglandin E2 by IL-13 gene therapy in rheumatoid arthritis synovium. J Immunol 2000;165(5):2755-63.

83. Woods JM, Amin MA, Katschke KJ Jr, Volin MV, Ruth JH, Connors MA, et al. Interleukin-13 gene therapy reduces inflammation, vascularization, and bony destruction in rat adjuvant-induced arthritis. Hum Gene Ther 2002;13(3):381-93.

84. Nabbe KC, van Lent PL, Holthuysen AE, Sloetjes AW, Koch AE, Radstake TR, et al. Local IL-13 gene transfer prior to immune-complex arthritis inhibits chondrocyte death and matrix-metalloproteinase-mediated cartilage matrix degradation despite enhanced joint inflammation. Arthritis Res Ther 2005;7(2):R392-401.

85. Woods JM, Tokuhira M, Berry JC, Katschke KJ Jr, Kurata H, Damergis JA Jr, et al. Interleukin-4 adenoviral gene therapy reduces production of inflammatory cytokines and prostaglandin E2 by rheumatoid arthritis synovium ex vivo. J Investig Med 1999;47(6):285-92.

86. Lubberts E, Joosten LA, van Den Bersselaar L, Helsen MM, Bakker AC, van Meurs JB, et al. Adenoviral vector-mediated overexpression of IL-4 in the knee joint of mice with collageninduced arthritis prevents cartilage destruction. J Immunol 1999;163(8):4546-56.

87. Lubberts E, Joosten LA, Chabaud M, van Den Bersselaar L, Oppers B, Coenen-De Roo CJ, et al. IL-4 gene therapy for collagen arthritis suppresses synovial IL-17 and osteoprotegerin ligand and prevents bone erosion. J Clin Invest 2000;105(12):1697-710.

88. Kim SH, Evans CH, Kim S, Oligino T, Ghivizzani SC, Robbins PD. Gene therapy for established murine collagen-induced arthritis by local and systemic adenovirus-mediated delivery of interleukin-4. Arthritis Res 2000;2(4):293-302.

89. Kageyama Y, Koide Y, Uchijima M, Nagata T, Yoshida A, Taiki A, et al. Plasmid encoding interleukin-4 in the amelioration of murine collagen-induced arthritis. Arthritis Rheum 2004;50(3):968-75.
90. Boyle DL, Nguyen KH, Zhuang S, Shi Y, McCormack JE, Chada S, et al. Intra-articular IL-4 gene therapy in arthritis: antiinflammatory effect and enhanced th2activity. Gene Ther 1999;6(12):1911-8.

91. Woods JM, Katschke KJ, Volin MV, Ruth JH, Woodruff DC, Amin MA, et al. IL-4 adenoviral gene therapy reduces inflammation, proinflammatory cytokines, vascularization, and bony destruction in rat adjuvant-induced arthritis. J Immunol 2001;166(2):1214-22.

92. Haas CS, Amin MA, Allen BB, Ruth JH, Haines GK III, Woods $\mathrm{JM}$, et al. Inhibition of angiogenesis by interleukin-4 gene therapy in rat adjuvant-induced arthritis. Arthritis Rheum 2006;54(8):2402-14

93. Bessis N, Cottard V, Saidenberg-Kermanac'h N, Lemeiter D, Fournier C, Boissier MC. Syngeneic fibroblasts transfected with a plasmid encoding interleukin-4 as non-viral vectors for antiinflammatory gene therapy in collagen-induced arthritis. J Gene Med 2002;4(3):300-7.

94. Saidenberg-Kermanac'h N, Bessis N, Lemeiter D, de Vernejoul MC, Boissier MC, Cohen-Solal M. Interleukin-4 cellular gene therapy and osteoprotegerin decrease inflammation-associated bone resorption in collagen-induced arthritis. J Clin Immunol 2004;24(4):370-8.

95. Guery L, Chiocchia G, Batteux F, Boissier MC, Fournier C. Collagen II-pulsed antigen-presenting cells genetically modified to secrete IL-4 down-regulate collagen-induced arthritis. Gene Ther 2001;8(24):1855-62.

96. Apparailly F, Verwaerde C, Jacquet C, Auriault C, Sany J, Jorgensen C. Adenovirus-mediated transfer of viral IL-10 gene inhibits murine collagen-induced arthritis. J Immunol 1998;160(11):5213-20.

97. Whalen JD, Lechman EL, Carlos CA, Weiss K, Kovesdi I, Glorioso JC, et al. Adenoviral transfer of the viral IL-10 gene periarticularly to mouse paws suppresses development of collagen-induced arthritis in both injected and uninjected paws. J Immunol 1999;162(6):3625-32.

98. Chernajovsky Y, Adams G, Triantaphyllopoulos K, Ledda MF, Podhajcer OL. Pathogenic lymphoid cells engineered to express TGF beta 1 ameliorate disease in a collagen-induced arthritis model. Gene Ther 1997;4(6):553-9.

99. Mi Z, Ghivizzani SC, Lechman E, Glorioso JC, Evans CH, Robbins PD. Adverse effects of adenovirus-mediated gene transfer of human transforming growth factor beta 1 into rabbit knees. Arthritis Res Ther 2003;5(3):R132-9.

100. Quattrocchi E, Dallman MJ, Feldmann M. Adenovirus-mediated gene transfer of CTLA-4Ig fusion protein in the suppression of experimental autoimmune arthritis. Arthritis Rheum 2000;43(8): 1688-97.

101. Ijima K, Murakami M, Okamoto H, Inobe M, Chikuma S, Saito I, et al. Successful gene therapy via intraarticular injection of adenovirus vector containing CTLA4IgG in a murine model of type II collagen-induced arthritis. Hum Gene Ther 2001;12(9):1063-77.

102. Yao Q, Wang S, Gambotto A, Glorioso JC, Evans CH, Robbins $\mathrm{PD}$, et al. Intra-articular adenoviral-mediated gene transfer of trail induces apoptosis of arthritic rabbit synovium. Gene Ther 2003;10(12):1055-60.

103. Liu Z, Xu X, Hsu HC, Tousson A, Yang PA, Wu Q, et al. CII-DC-AdTRAIL cell gene therapy inhibits infiltration of CII-reactive $\mathrm{T}$ cells and CII-induced arthritis. J Clin Invest 2003;112(9):1332-41.

104. Terzioglu E, Bisgin A, Sanlioglu AD, Ulker M, Yazisiz V, Tuzuner S, et al. Concurrent gene therapy strategies effectively destroy synoviocytes of patients with rheumatoid arthritis. Rheumatology (Oxford) 2007;46(5):783-9. 
105. Zhang H, Yang Y, Horton JL, Samoilova EB, Judge TA, Turka LA, et al. Amelioration of collagen-induced arthritis by CD95 (Apo-1/ Fas)-ligand gene transfer. J Clin Invest 1997;100(8):1951-7.

106. Okamoto K, Asahara H, Kobayashi T, Matsuno H, Hasunuma T, Kobata $\mathrm{T}$, et al. Induction of apoptosis in the rheumatoid synovium by Fas ligand gene transfer. Gene Ther 1998;5(3):331-8.

107. Zhang H, Gao G, Clayburne G, Schumacher HR. Elimination of rheumatoid synovium in situ using a Fas ligand 'gene scalpel'. Arthritis Res Ther 2005;7(6):R1235-43.

108. Kim SH, Kim S, Oligino TJ, Robbins PD. Effective treatment of established mouse collagen-induced arthritis by systemic administration of dendritic cells genetically modified to express FasL. Mol Ther 2002;6(5):584-90.

109. Kobayashi T, Okamoto K, Kobata T, Hasunuma T, Kato T, Hamada $\mathrm{H}$, et al. Novel gene therapy for rheumatoid arthritis by FADD gene transfer: induction of apoptosis of rheumatoid synoviocytes but not chondrocytes. Gene Ther 2000;7(6):527-33.

110. Colville-Nash PR, Scott DL. Angiogenesis and rheumatoid arthritis: pathogenic and therapeutic implications. Ann Rheum Dis 1992;51(7):919-25.

111. Kimball ES, Gross JL. Angiogenesis in pannus formation. Agents Actions 1991;34(3-4):329-31.

112. Gerlag DM, Borges E, Tak PP, Ellerby HM, Bredesen DE, Pasqualini R, et al. Suppression of murine collagen-induced arthritis by targeted apoptosis of synovial neovasculature. Arthritis Res 2001;3(6):357-61.

113. Kim JM, Ho SH, Park EJ, Hahn W, Cho H, Jeong JG, et al. Angiostatin gene transfer as an effective treatment strategy in murine collagen-induced arthritis. Arthritis Rheum 2002;46(3):793-801.

114. Chen Y, Donnelly E, Kobayashi H, Debusk LM, Lin PC. Gene therapy targeting the Tie2 function ameliorates collageninduced arthritis and protects against bone destruction. Arthritis Rheum 2005;52(5):1585-94.

115. Afuwape AO, Feldmann M, Paleolog EM. Adenoviral delivery of soluble VEGF receptor 1 (sFlt-1) abrogates disease activity in murine collagen-induced arthritis. Gene Ther 2003;10(23): 1950-60.

116. Jou IM, Shiau AL, Chen SY, Wang CR, Shieh DB, Tsai CS, et al. Thrombospondin 1 as an effective gene therapeutic strategy in collagen-induced arthritis. Arthritis Rheum 2005;52(1): 339-44.

117. Park YW, Kang YM, Butterfield J, Detmar M, Goronzy JJ, Weyand CM. Thrombospondin 2 functions as an endogenous regulator of angiogenesis and inflammation in rheumatoid arthritis. Am J Pathol 2004;165(6):2087-98.

118. Apparailly F, Bouquet C, Millet V, Noel D, Jacquet C, Opolon $\mathrm{P}$, et al. Adenovirus-mediated gene transfer of urokinase plasminogen inhibitor inhibits angiogenesis in experimental arthritis. Gene Ther 2002;9(3):192-200.

119. Rutkauskaite E, Volkmer D, Shigeyama Y, Schedel J, Pap G, Muller-Ladner U, et al. Retroviral gene transfer of an antisense construct against membrane type 1 matrix metalloproteinase reduces the invasiveness of rheumatoid arthritis synovial fibroblasts. Arthritis Rheum 2005;52(7):2010-4.

120. Rutkauskaite E, Zacharias W, Schedel J, Muller-Ladner U, Mawrin C, Seemayer CA, et al. Ribozymes that inhibit the production of matrix metalloproteinase 1 reduce the invasiveness of rheumatoid arthritis synovial fibroblasts. Arthritis Rheum 2004;50(5):1448-56.

121. van der Laan WH, Quax PH, Seemayer CA, Huisman LG, Pieterman EJ, Grimbergen JM, et al. Cartilage degradation and invasion by rheumatoid synovial fibroblasts is inhibited by gene transfer of TIMP-1 and TIMP-3. Gene Ther 2003;10(3):234-42.

122. Tomita T, Takeuchi E, Tomita N, Morishita R, Kaneko M, Yamamoto K, et al. Suppressed severity of collagen-induced arthritis by in vivo transfection of nuclear factor kappaB decoy oligodeoxynucleotides as a gene therapy. Arthritis Rheum 1999;42(12):2532-42.

123. Zhang HG, Huang N, Liu D, Bilbao L, Zhang X, Yang P, et al. Gene therapy that inhibits nuclear translocation of nuclear factor kappaB results in tumor necrosis factor alpha-induced apoptosis of human synovial fibroblasts. Arthritis Rheum 2000;43(5): 1094-105.

124. Tas SW, Adriaansen J, Hajji N, Bakker AC, Firestein GS, Vervoordeldonk MJ, et al. Amelioration of arthritis by intraarticular dominant negative Ikk beta gene therapy using adenoassociated virus type 5. Hum Gene Ther 2006;17(8):821-32.

125. Shouda T, Yoshida T, Hanada T, Wakioka T, Oishi M, Miyoshi $\mathrm{K}$, et al. Induction of the cytokine signal regulator SOCS3/CIS3 as a therapeutic strategy for treating inflammatory arthritis. J Clin Invest 2001;108(12):1781-8.

126. Takayanagi H, Juji T, Miyazaki T, lizuka H, Takahashi T, Isshiki M, et al. Suppression of arthritic bone destruction by adenovirus-mediated csk gene transfer to synoviocytes and osteoclasts. J Clin Invest 1999;104(2):137-46.

127. Yamamoto A, Fukuda A, Seto H, Miyazaki T, Kadono Y, Sawada Y, et al. Suppression of arthritic bone destruction by adenovirus-mediated dominant-negative Ras gene transfer to synoviocytes and osteoclasts. Arthritis Rheum 2003;48(9): 2682-92.

128. Rabinovich GA, Daly G, Dreja H, Tailor H, Riera CM, Hirabayashi J, et al. Recombinant galectin- 1 and its genetic delivery suppress collagen-induced arthritis via $\mathrm{T}$ cell apoptosis. J Exp Med 1999;190(3):385-98.

129. Schedel J, Seemayer CA, Pap T, Neidhart M, Kuchen S, Michel $\mathrm{BA}$, et al. Targeting cathepsin $\mathrm{L}(\mathrm{CL})$ by specific ribozymes decreases CL protein synthesis and cartilage destruction in rheumatoid arthritis. Gene Ther 2004;11(13):1040-7.

130. Nonomura Y, Kohsaka H, Nasu K, Terada Y, Ikeda M, Miyasaka N. Suppression of arthritis by forced expression of cyclindependent kinase inhibitor p21(Cip1) gene into the joints. Int Immunol 2001;13(6):723-31.

131. Taniguchi K, Kohsaka H, Inoue N, Terada Y, Ito H, Hirokawa $\mathrm{K}$, et al. Induction of the p16INK4a senescence gene as a new therapeutic strategy for the treatment of rheumatoid arthritis. Nat Med 1999;5(7):760-7.

132. Triantaphyllopoulos KA, Williams RO, Tailor H, Chernajovsky Y. Amelioration of collagen-induced arthritis and suppression of interferon-gamma, interleukin-12, and tumor necrosis factor alpha production by interferon-beta gene therapy. Arthritis Rheum 1999;42(1):90-9.

133. Dai L, Claxson A, Marklund SL, Feakins R, Yousaf N, Chernajovsky $\mathrm{Y}$, et al. Amelioration of antigen-induced arthritis in rats by transfer of extracellular superoxide dismutase and catalase genes. Gene Ther 2003;10(7):550-8.

134. Iyama S, Okamoto T, Sato T, Yamauchi N, Sato Y, Sasaki K, et al. Treatment of murine collagen-induced arthritis by ex vivo extracellular superoxide dismutase gene transfer. Arthritis Rheum 2001;44(9):2160-7.

135. Adriaansen J, Fallaux FJ, de Cortie CJ, Vervoordeldonk MJ, Tak PP. Local delivery of beta interferon using an adeno-associated virus type 5 effectively inhibits adjuvant arthritis in rats. J Gen Virol 2007;88(Pt 6):1717-21.

136. Shiau AL, Chen SY, Chang MY, Su CH, Chung SY, Yo YT, et al. Prothymosin alpha lacking the nuclear localization signal as an effective gene therapeutic strategy in collagen-induced arthritis. J Immunol 2007;178(7):4688-94.

137. Raper SE, Chirmule N, Lee FS, Wivel NA, Bagg A, Gao GP, et al. Fatal systemic inflammatory response syndrome in a ornithine transcarbamylase deficient patient following adenoviral gene transfer. Mol Genet Metab 2003;80(1-2):148-58. 